\title{
EMPREENDEDORISMO FEMININO: UMA ANÁLISE DESCRITIVA E COMPARATIVA ENTRE ORGANIZAÇÓES ADMINISTRADAS POR MULHERES E POR HOMENS
}

\author{
FEMALE ENTREPRENEURSHIP: A DESCRIPTIVE AND COMPARATIVE ANALYSIS BETWEEN \\ ORGANIZATIONS ADMINISTERED BY WOMEN AND MEN
}

\begin{abstract}
Ana Paula Pessotto
Universidade Regional Integrada do Alto Uruguai e das Missões, Frederico Westphalen, RS, Brasil, ana.pessotto87@ gmail.com
\end{abstract}

\section{Neimar Ferreira da Rosa}

Instituto Federal do Rio Grande do Sul, Bento Gonçalves, RS, Brasil, neimarferreira@gmail.com

\section{Cintia Sonale Rebonatto}

Faculdade Meridional, Passo Fundo, RS, Brasil, cintiasonale@gmail.com

\section{Carlos Costa}

Faculdade Meridional, Passo Fundo, RS, Brasil, carlos.costa1@gmail.com

\begin{abstract}
Resumo: Dado os indicadores socioeconômicos e demográficos da região do Médio Alto Uruguai e a reconhecida contribuiçáo econômica do empreendedorismo feminino para os países em desenvolvimento, este estudo pretende realizar uma análise comparativa dos empreendimentos administrados por mulheres com os administrados por homens na regiáo. Para coleta de dados utilizou-se de dados secundários, onde foram selecionadas aleatóriamente 400 dessas empresas. Os resultados deste estudo permitiram identificar que as mulheres da região são maioria na gestão das empresas e atuam principalmente no segmento comercial, mas ainda empregam menos que as empresas administradas por homens. O estudo contribui com outros focados no empreendedorismo da mulher, com implicaçóes teóricas e práticas, no intuito de estimular a qualificaçóes desses negócios e a garantir a sua sobrevivência.
\end{abstract}

Palavras-chave: Empreendedorismo; Empreendedorismo Feminino; Mulheres.

Abstract: Given the socioeconomic and demographic indicators of the Middle Upper Uruguay region and the recognized economic contribution of female entrepreneurship to developing countries, this study intends to carry out a comparative analysis of enterprises managed by women with those managed by men in the region. For data collection, secondary data were used, where 400 of these companies were randomly selected. The results of this study allowed us to identify that women in the region are the majority in the management of companies and work mainly in the commercial segment, but still employ less than companies managed by men. The study contributes with others focused on women's entrepreneurship, with theoretical and practical implications, in order to stimulate the qualifications of these businesses and guarantee their survival.

Keywords: Entrepreneurship; Female Entrepreneurship; Women. 


\section{Introdução}

As transformaçóes do mercado de trabalho e das famílias estimularam a inserção da mulher no âmbito organizacional, por muito tempo dominado pelo gênero masculino caracterizado, em muitos aspectos, pelo machismo e patriarcalismo. Assim, com o passar dos anos e com as várias transformaçóes da sociedade, as mulheres passaram a assumir diversas responsabilidades para além do cuidado do lar e da família, ampliando sua participação como força de trabalho, o que refletiu no aumento do seu poder de compra e do número de negócios fundados e administrados por mulheres (AVENI; NUNES; CRUZ, 2012). Dessa forma, como consumidoras ou empreendedoras, as mulheres têm representado uma importante força da economia mundial.

O empreendedorismo feminino tem sido considerado uma estratégia importante para a redução da pobreza e para o desenvolvimento social dos países emergentes (GEM, 2017). Exemplo disso, no Brasil, no ano de 2016, 51,5\% dos negócios que iniciaram eram administrados por mulheres e, ao considerar a última década, os percentuais têm se mantido muito próximos dos negócios fundados por homens, o que indica um avanço significativo da participação feminina na atividade econômica nacional (GEM, 2017). No entanto, embora a iniciativa em empreender seja semelhante entre os gêneros, ocorrem indicativos que o desempenho dos negócios administrados por mulheres é inferior aos administrados por homens. Esse fator é evidenciado quando apenas 42,7\% dos negócios com mais de 3,5 anos de funcionamento são administrados por mulheres, uma diferença de 14,6\% entre os gêneros (GEM, 2017).

Considerando tais indicadores e a tendência contemporânea de empreendedorismo feminino, pontua-se a necessidade de maiores investimentos em pesquisas e programas de apoio as empreendedoras com negócios já estabelecidos. É nessa direção que se destaca a premência em melhor reconhecer a participação da mulher na realidade socioeconômica da região do Estado do Rio Grande do Sul (RS) classificada pelo Conselho Regional de Desenvolvimento (Corede), como Região do Médio Alto Uruguai ou Conselho Regional de Desenvolvimento do Médio Alto Uruguai (Codemau).

A referida regiáo localiza-se no extremo norte do RS e é formada por 22 municípios, apresentando um Produto Interno Bruto (PIB) de R \$ 3.041.162.709,00, o que corresponde a uma participação de 0,92\% no PIB do Estado e um PIB per capta de R $19.501,00$. Os setores com maior representatividade na dinâmica da economia regional dessa área são os de serviços, seguido pela indústria e a agropecuária. $\mathrm{O}$ setor do comércio, por sua vez, é o responsável pelo maior número de vínculos empregatícios (26,32\%), em segundo lugar aparece a indústria $(25,10 \%)$, seguida pelo setor de serviços $(8,66 \%)$, sendo a agropecuária e a pesca os ramos que menos empregam (2,21\%). As características demográficas da Região do Médio Alto Uruguai denotam uma população total de 151.557 habitantes, com aumento da população feminina, representando em 2012, 50,02\% da população (CODEMAU, 2017).

Assim, considerando a relevância demográfica das mulheres na referida região e a sua reconhecida contribuição econômica para os países em desenvolvimento, este estudo objetiva realizar uma análise comparativa dos empreendimentos administrados por mulheres com aqueles geridos por homens nesse contexto. Para tanto, empreendeu-se uma pesquisa de cunho descritivo, de abordagem quantitativa e de corte transversal, coletando-se dados secundários de uma amostra aleatória de 400 empresas em operação na regiāo do Médio Alto Uruguai, dentre as 1020 organizaçôes com faturamento anual de até $\mathrm{R} \$ 360.000,00$ 
(classificadas como micro e pequenas empresas), cadastradas no banco de dados do Programa Negócio a Negócio, de responsabilidade do Sebrae no ano de 2017. A partir deste foi possível obter as informaçôes socioeconômicas dos empreendimentos (atividade econômica principal, número de funcionários, tipo de empresa, localização, data de abertura e segmento de atuação) e características sociodemográficas dos proprietários da empresa (data de nascimento, sexo, escolaridade e experiência empresarial). A análise dos dados foi instrumentalizada pelo software SPSS (v. 20), utilizando análises estatísticas descritivas baseadas na mensuração da amostra.

A síntese do trabalho realizado é apresentada neste estudo organizado em quatro partes principais. Esta primeira que apresenta e delimita o assunto, apresentando suas questôes norteadoras e objetivos e, na sequência, o referencial teórico que aborda conceitos essenciais referentes, no geral, ao empreendedorismo e, em específico, aquele praticado pelo público feminino para, depois, expor alguns resultados de pesquisas já empreendidas por autores diversos (HARVESTON; DAVIS; LYDEN, 1997; DANES; STAFFORD; LOY, 2007; LUSSIER; SONFIELD, 2007; SMITH, 2009, 2014; CRUZ; JUSTO; CASTRO, 2012; AMORE; GAROFALO; MINICHILLI, 2014) revelando dados comparativos entre o empreendedorismo feminino e o masculino. Na sequência apresenta-se e discute-se os dados secundários coletados para, em seguida, tecer-se as consideraçôes finais e expor limitaçôes e indicaçôes de futuras pesquisas, na busca por fomentar dados que contribuam com o desenvolvimento da regiáo e a contribuição da mulher em função de seu poder empreendedor.

\section{Resultados do empreendedorismo feminino quando comparado com o masculino}

O empreendedorismo em relação à criação de negócios, pode ser definido como o envolvimento de pessoas e processos que, em conjunto, levam à transformação de ideias em oportunidades, e a implementação dessas oportunidades gera como resultado a criação dos empreendimentos (DORNELAS, 2014). Ainda, em relação a definiçáo de empreendedorismo, o mesmo, pode ser entendido como um processo no qual se realiza algo criativo e inovador, objetivando a geraçáo de riqueza e valor para os indivíduos e para a sociedade (SHANE; VENKATARAMAN, 2000; DORNELAS, 2014).

Nesse contexto, o termo empreendedor é utilizado para se referir principalmente a pessoa que se dedica à geração de riqueza, seja na transformação de conhecimentos em produtos ou serviços, na geração do próprio conhecimento ou na inovaçáo em áreas diversas (DOLABELA, 2008). Dessa forma, os empreendedores são vistos, geralmente, como atores capazes de transformar a ordem econômica existente em uma nova ordem econômica, pela introdução de novos produtos ou serviços, ou ainda, pela introdução de novas formas de negócios ou pela utilização de novos materiais. (SCHUMPETER, 1971).

Quando indivíduos são capazes de identificas oportunidades de negócios no ambiente em que atuam, e utilizar as suas capacidades para explorá-las, toda a sociedade é beneficiada, seja com o aumento da criação de empregos, ou com o aumento da riqueza do país. Pois, com o esforço individual ou coletivo na criação de um novo negócio, ou mesmo na expansão de uma empresa já existente, toda a sociedade é beneficiada (GEM, 2011; HISRICH; PETERS; SHEPHERD, 2014). Assim, quando uma sociedade reconhece como um de seus valores a importância das ações referentes à ações empreendedoras, com a geração de novos negócios, mais indivíduos são sensibilizados pelo empreendedorismo (DOLABELA, 2008). 
Para Dornelas (2014), além dos atributos tradicionais típicos de administradores, os empreendedores são visionários, indivíduos que fazem a diferença, sabem explorar as oportunidades, sáo determinados e dinâmicos, dedicados ao trabalho, otimistas e apaixonados pelo que fazem. $\mathrm{O}$ autor cita, ainda, serem os empreendedores independentes e construtores do próprio destino, acreditando que o dinheiro é consequência do sucesso nos negócios, possuem liderança incomum, sabem construir uma rede de relacionamentos externos à empresa e planejam cada passo do investimento. Também, possuem conhecimento, assumem riscos calculados e criam valor para a sociedade na qual o empreendimento encontra-se inserido, em busca de soluçóes para melhorar a vida das pessoas. Segundo Drucker (1987; 1996), empreendedor é a pessoa que inicia e ou opera um negócio para realizar uma ideia ou projeto pessoal assumindo riscos e responsabilidades e inovando continuamente.

Nessa perspectiva, destaca-se o aumento do número de mulheres que estáo empreendendo (GEM, 2016). Elas estão se arriscando mais e geralmente estão começando seus negócios sozinhas. Estudos realizados no Brasil apontam que as empreendedoras geralmente são mulheres experientes, altamente escolarizadas, casadas, começaram sozinhas e as experiências adquiridas nos trabalhos anteriores ajudam na administração de seus negócios (SILVA; LASSO; MAINARDES, 2016).

Pesquisa empreendida por Alperstedt, Ferreira e Serafim (2014) revela que os principais problemas encontrados ao longo do processo empreendedor de mulheres foram pessoais e familiares, financeiros, dificuldades de gestão, falta de credibilidade e dificuldades de mercado. Isso pode ser explicado, dentre tantos motivos, pelo fato de as habilidades de gerenciamento, como marketing e finanças, e conhecimento tecnológico, precisarem de aprimoramento, pois a maioria das empreendedoras assume que não tem conhecimento suficiente em tais áreas (ALPERSTEDT; FERREIRA; SERAFIM, 2014; SILVA; LASSO; MAINARDES, 2016). Além disso, de acordo com os referidos estudos, as mulheres têm tido dificuldade na obtenção de empréstimos, por isso, priorizam a utilização de fonte própria de recursos.

Revela o trabalho de Alperstedt, Ferreira e Serafim (2014), ainda, que a conciliação dos múltiplos papéis - de mãe, esposa e empreendedora - é uma das dificuldades mais destacadas. Apesar disso, as empreendedoras, nesse estudo, destacam que as suas jornadas foram marcadas por uma dose de sonho, força de vontade, mas, acima de tudo, de muito trabalho e empenho.

As características pessoais das mulheres são consideradas os principais impulsionadores da carreira empresarial das mulheres. Fatores como imaginação empreendedora, empatia, modularidade e auto-organização (BARRETT, 2014), atuam como impulsionadores do ingresso empresarial feminino. Essas são complementadas por variáveis de capital humano, como nível educacional e área, experiência empreendedora anterior (HISRICH; FÜLÖP, 1997) e agilidade, ou seja, a capacidade das mulheres de identificar oportunidades e explorar os recursos necessários à sua estratégia empreendedora (KICKUL, et al., 2010).

O desempenho de empresas controladas por mulheres é afetado positivamente pela idade da empresária (ZAPALSKA; NIEWIADOMSKA-BUGAJ; RUDD, 2005) e sua capacidade de obter apoio familiar, uma condição relevante para lidar com problemas pessoais e comerciais (WELSH, et al., 2014). A tradição e a cultura familiar são, assim, fatores que afetam assertivamente a probabilidade de uma mulher se tornar uma empresária (GUNDRY; BEN-YOSEPH, 1998; ROBINSON; STUBBERUD, 2012), sendo o empreendedorismo feminino fortemente corroborado pela família de origem (WELSH, 
et al., 2013; WELSH et al., 2014) - seja com apoio moral ou com capital social (BURT, 1997; SIRMON; HITT, 2003; PEARSON; CARR; SHAW, 2008).

Diante dos aspectos positivos e de pujança do empreendedorismo feminino e das questóes lacunares à atividade, emerge a necessidade de se conhecer, sob o ponto de vista de autores que já se investiram nessa busca, dados comparativos entre os diferentes gêneros. Tarefa que se empreende a seguir.

Cole e Johnson (2007), pesquisaram sobre empresas abertas entre cônjuges, empreendimentos onde atuam um casal, buscando compreender a estrutura de governança e os mecanismos a ela relacionados. Concluíram que a confiança engendrada no negócio através da conexão emocional dos casais, sinergia e compromisso com o negócio, ajudam os casais a continuar trabalhando juntos, até mesmo após o divórcio, constituindo benefícios para a longevidade da empresa.

No entanto, de maneira comparativa, grande mote deste estudo, Smith (2009, 2014) conclui que as mulheres tendem a preferir iniciar empresas em campos mais familiares, enquanto os homens podem explorar outros menos próximos. Além disso, as empresas pertencentes a mulheres geralmente se concentram em uma indústria, enquanto aquelas pertencentes a homens são mais propensas a implementar maior diversificação.

Amore, Garofalo e Minichilli (2014) constatam que as empresas lideradas por mulheres têm um desempenho significativamente melhor em altos níveis de diretoria feminina (ou seja, porcentagem de diretores do sexo feminino). Similarmente, Cruz et al. (2012) concluem que as mulheres gestoras sabem lidar melhor com conflitos socioemocionais e financeiros do que os homens, melhorando, assim, o desempenho das empresas. Igualmente, Danes et al. (2007) concluem que o gênero dos empresários interage com as práticas de gerenciamento para influenciar o desempenho. Em particular, as práticas de gestão de pessoal têm um efeito muito maior sobre a receita bruta para proprietários do sexo feminino do que do sexo masculino.

Lussier e Sonfield (2007) analisam as relaçôes entre o tempo gasto em atividades de gestão estratégica e o percentual de mulheres envolvidas em operaçóes firmes, mas encontram resultados não significativos. Harveston, Davis, Lyden (1997) concluem que o gênero do proprietário do negócio interage com algumas variáveis organizacionais para influenciar a abrangência do processo de planejamento da sucessão e seus direcionadores. Em particular, o tamanho e a formalidade organizacionais têm um efeito mais forte sobre as empresas lideradas por mulheres do que em empresas lideradas por homens.

Ante a variada gama de resultados comparativos entre o empreendedorismo de homens e mulheres em contextos diversos, parte-se por apresentar os dados que permitem concluir sobre esse fenômeno na regiāo específica do Médio Alto Uruguai, retomando-se o problema de pesquisa: existem diferenças significativas em empreendimentos administrados por mulheres em relação àqueles geridos por homens na referida região?

\section{Apresentação e análise dos resultados}

Os dados aqui apresentados referem-se à amostra aleatória de 400 empresas cadastradas no Programa Negócio a Negócio (SEBRAE, 2017) em operação na região do Corede Médio Alto Uruguai. 
Esses tratam, primeiramente, da caracterização sociodemográfica dos empreendedores (3.1) e, após, sobre as informaçôes socioeconômicas dos empreendimentos (3.2).

\subsection{Caracterização sociodemográfica dos empreendedores}

A coleta e análise dos dados revelou que a maioria das empresas é administrada por mulheres (54,7\%), os outros 45,3\% referem-se a empresas que têm homens a frente de sua gestão. Assim, os dados permitiram verificar que a idade média dos empreendedores da região é de 42,5 anos, e a maioria deles tem entre 31 e 50 anos. Quando a análise se dá por gênero, percebe-se que as mulheres empreendedoras são mais jovens em relação aos homens, com uma diferença média de 1,7 anos (Tabela 1). Este fator pode interferir no desempenho da empresa uma vez que, o desempenho de empresas controladas por mulheres é afetado positivamente pela idade da empresária (ZAPALSKA; NIEWIADOMSKA-BUGAJ; RUDD, 2005).

Tabela 1: Faixa etária dos empreendedores

\begin{tabular}{|c|c|c|c|c|c|c|}
\hline \multirow[b]{2}{*}{ Idade } & \multicolumn{2}{|c|}{ Geral } & \multicolumn{2}{|c|}{$\begin{array}{c}\text { Empresas administradas por } \\
\text { homens }\end{array}$} & \multicolumn{2}{|c|}{$\begin{array}{c}\text { Empresas administradas por } \\
\text { mulheres }\end{array}$} \\
\hline & $\mathrm{n}$ & $\%$ & $\mathrm{~N}$ & $\%$ & $\mathrm{n}$ & $\%$ \\
\hline Até 20 anos & 11 & 2,8 & 5 & 2,8 & 6 & 2,7 \\
\hline 21 a 30 anos & 81 & 20,2 & 33 & 18,2 & 48 & 21,9 \\
\hline 31 a 40 anos & 95 & 23,7 & 44 & 24,3 & 51 & 23,3 \\
\hline 41 a 50 anos & 92 & 23 & 39 & 21,5 & 53 & 24,2 \\
\hline 51 a 60 anos & 84 & 21 & 38 & 21 & 46 & 21 \\
\hline 61 a 70 anos & 30 & 7,5 & 17 & 9,3 & 13 & 6 \\
\hline 71 a 80 anos & 5 & 1,3 & 4 & 2,2 & 1 & 0,4 \\
\hline Acima 81 anos & 2 & 0,5 & 1 & 0,5 & 1 & 0,4 \\
\hline Total & 400 & 100 & 181 & 100 & 219 & 100 \\
\hline Média idade & \multicolumn{2}{|c|}{42,5} & \multicolumn{2}{|c|}{43,4} & \multicolumn{2}{|c|}{41,7} \\
\hline
\end{tabular}

Fonte: Dados secundários produzidos pelos autores (2018).

Outro dado relevante analisado diz respeito à formaçáo dos empreendedores. Quase metade deles tem apenas ensino médio (49,3\%). No entanto, na análise por gênero, identificou-se que as mulheres são mais escolarizadas, ainda que a maioria delas possua apenas ensino médio $(45,2 \%)$, há uma parcela representativa que tem o ensino superior ou pós-graduação (41,1\%), enquanto os homens que acessaram esse nível de formação representam apenas 26,5\% dos empreendedores (Tabela 2). 
Tabela 2: Escolaridade dos empreendedores

\begin{tabular}{lcccccc}
\hline & \multicolumn{2}{c}{ Dados gerais } & \multicolumn{2}{c}{$\begin{array}{c}\text { Empresas administradas por } \\
\text { homens }\end{array}$} & $\begin{array}{c}\text { Empresas administradas por } \\
\text { mulheres }\end{array}$ \\
\hline Fundamental incompleto & 29 & 7,2 & 19 & 10,5 & 10 & $\%$ \\
Fundamental completo & 26 & 6,5 & 10 & 5,5 & 16 & 7,3 \\
Médio incompleto & 10 & 2,5 & 6 & 3,3 & 4 & 1,8 \\
Médio completo & 197 & 49,3 & 98 & 54,1 & 99 & 45,2 \\
Superior incompleto & 46 & 11,5 & 20 & 11,0 & 26 & 11,9 \\
Superior completo & 73 & 18,3 & 25 & 13,8 & 48 & 21,9 \\
Especialização & 18 & 4,5 & 3 & 1,7 & 15 & 6,8 \\
Mestrado & 1 & 0,3 & 0 & 0,0 & 1 & 0,5 \\
Total & 400 & 100 & 181 & 100 & 219 & 100 \\
\hline
\end{tabular}

Fonte: Dados secundários produzidos pelos autores (2018).

Esses dados revelam um percentual de mulheres empreendedoras melhores qualificadas na região em estudo, o que corrobora com o estudo de Silva, Lasso e Mainardes (2016), ao evidenciarem que as empreendedoras geralmente são mulheres com experiências adquiridas nos trabalhos anteriores e altamente escolarizadas, fatores que ajudam na administração de seus negócios.

\subsection{Comparação entre as empresas administradas por mulheres com as geridas pelos homens}

Analisando-se alguns indicadores disponíveis no banco de dados acessado referente às características das 400 empresas que compuseram a amostra do estudo, pode-se observar que em relação ao número de empregados, a maior parte emprega apenas uma pessoa (30,5\%) e em $23 \%$ delas o empreendedor atua sozinho. Esses números se justificam pelo porte das empresas, que na sua totalidade são micro e pequenas. Além disso, é possível dizer que as organizaçôes pesquisadas administradas por mulheres empregam, em média, menos pessoas do que as geridas por homens. Em média 15\% das empresas administradas pelos empreendedores homens empregam mais de quatro funcionários, contra 12,5\% daquelas que têm as mulheres na sua gestão, sendo que $87,5 \%$ das empreendedoras atuam sozinhas ou empregam até três funcionários (Tabela 3). 
Revista GESTO: Revista de Gestão Estratégica de Organizaçóes

Santo Ângelo | v. 9 | n. 2 | p. 101-113 | jul./dez. 2021 | DOI: http://dx.doi.org/10.31512/gesto.v9i2.342

Tabela 3: Número de empregados nas empresas

\begin{tabular}{ccccccc}
\hline & \multicolumn{2}{c}{ Geral } & \multicolumn{2}{c}{$\begin{array}{c}\text { Empresas administradas por } \\
\text { homens }\end{array}$} & \multicolumn{2}{c}{ Empresas administradas por } \\
mulheres
\end{tabular}

Fonte: Dados secundários produzidos pelos autores (2018).

O tempo de atuação das empresas analisadas, com base no ano de sua fundação, é em média, 13,7 anos. Além disso, as empresas administradas por mulheres são, em média, 1,7 anos mais recentes do que as empresas administradas por homens. Ainda, chama atenção o fato de que o percentual de empresas fundadas por mulheres $(24,6 \%)$ é maior do que as administradas por homens $(22,7 \%)$ nos últimos cinco anos. Esse dado parece relevar que o empreendedorismo feminino tem se fortalecido nos últimos anos (Tabela 4).

Tabela 4: Tempo de fundação da empresa

\begin{tabular}{|c|c|c|c|c|c|c|}
\hline \multirow{2}{*}{$\begin{array}{c}\text { Tempo de } \\
\text { empresa }\end{array}$} & \multicolumn{2}{|c|}{ Geral } & \multicolumn{2}{|c|}{$\begin{array}{l}\text { Empresas administradas por } \\
\text { homens }\end{array}$} & \multicolumn{2}{|c|}{$\begin{array}{c}\text { Empresas administradas por } \\
\text { mulheres }\end{array}$} \\
\hline & $\mathrm{n}$ & $\%$ & $\frac{n}{5}$ & $\%$ & $n$ & $\%$ \\
\hline 2 anos & 18 & 4,5 & 6 & 3,3 & 12 & 5,5 \\
\hline 3 anos & 20 & 5 & 7 & 3,9 & 13 & 5,9 \\
\hline 4 anos & 18 & 4,5 & 7 & 3,9 & 11 & 5 \\
\hline 5 anos & 28 & 7 & 16 & 8,8 & 12 & 5,5 \\
\hline 6 a 10 anos & 77 & 19,3 & 30 & 16,6 & 47 & 21,5 \\
\hline 11 a 15 anos & 90 & 22,5 & 44 & 24,3 & 46 & 21 \\
\hline
\end{tabular}




\begin{tabular}{|c|c|c|c|c|c|}
\hline 16 a 20 anos & 44 & 11 & 18 & 9,9 & 26 \\
\hline 21 a 30 anos & 65 & 16,2 & 32 & 17,7 & 33 \\
\hline 31 anos ou mais & 29 & 7,2 & 16 & 8,8 & 16 \\
\hline Total & 400 & 100 & 181 & 100 & 219 \\
\hline Média idade & & & & & \\
\hline
\end{tabular}

Fonte: Dados secundários produzidos pelos autores (2018).

As análises sobre o segmento revelaram que, na região considerada para o estudo, o comércio se destaca, representando 81,8\% das empresas da amostra. Em seguida aparece o segmento de serviços $(14,7 \%)$ e a indústria $(3,5 \%)$. Esses resultados variam pouco entre os gêneros, apenas com participação maior das mulheres no comércio $(85,8 \%$, contra $76,8 \%)$ e dos homens no segmento de serviços $(19,9 \%$ contra 10,5\%), conforme tem-se à Tabela 5.

Tabela 5: Segmento de atuação das empresas

\begin{tabular}{|c|c|c|c|c|c|c|}
\hline \multicolumn{3}{|c|}{ Geral } & \multicolumn{2}{|c|}{$\begin{array}{l}\text { Empresas administradas por } \\
\text { homens }\end{array}$} & \multicolumn{2}{|c|}{$\begin{array}{c}\text { Empresas administradas por } \\
\text { mulheres }\end{array}$} \\
\hline & $\frac{n}{227}$ & $\%$ & $\frac{\mathrm{N}}{120}$ & $\%$ & $\frac{n}{180}$ & $\%$ \\
\hline Comércio & 327 & 81,8 & 139 & 76,8 & 188 & 85,8 \\
\hline Indústria & 14 & 3,5 & 6 & 3,3 & 8 & 3,7 \\
\hline Serviços & 59 & 14,7 & 36 & 19,9 & 23 & 10,5 \\
\hline Total & 400 & 100 & 181 & 100 & 219 & 100 \\
\hline
\end{tabular}

Fonte: Dados secundários produzidos pelos autores (2018).

Esses resultados divergem de estudos anteriores que identificaram que as empresas pertencentes a mulheres geralmente se concentram na indústria e aquelas administradas por homens tendem a ser em segmentos diversos (SMITH, 2009; SMITH, 2014).

A análise realizada através do código de Classificação Nacional de Atividades Econômicas (CNAE) permite inferir em que tipo de atividades os empreendedores têm investido mais. Interessante notar que os homens têm empreendido em atividades relacionadas a peças automotivas (13,3\%), restaurantes $(7,7 \%)$ e reparação automotiva $(6,1 \%)$. As mulheres, por sua vez, investem mais em atividades consideradas mais femininas, como é o caso do varejo de roupas $(23,3 \%)$, contudo chama atenção o fato de investirem em empresas de peças automotivas $(5,5 \%)$ consideradas um segmento mais masculino, conforme Tabela 6 . Uma explicação para isso pode ser o fato de algumas mulheres atuarem em conjunto com o seu cônjuge (COLE; JOHNSON, 2007). 
Revista GESTO: Revista de Gestão Estratégica de Organizaçôes

Santo Ângelo | v. 9 | n. 2 | p. 101-113 | jul./dez. 2021 | DOI: http://dx.doi.org/10.31512/gesto.v9i2.342

Tabela 7: Atividade principal da empresa de acordo com a Classificação Nacional de Atividades Econômicas (CNAE)

\begin{tabular}{|c|c|c|c|c|c|c|c|c|}
\hline \multirow[b]{2}{*}{ Ranking } & \multicolumn{4}{|c|}{ Empresas Administradas por Homens } & \multicolumn{4}{|c|}{ Empresas Administradas por Mulheres } \\
\hline & Código & Atividade & $\mathrm{n}$ & $\%$ & Código & Atividade & $\mathrm{n}$ & $\%$ \\
\hline $1^{\circ}$ & 4530 & Peças automotivas & 24 & 13,3 & 4781 & Varejo de roupas & 51 & 23,3 \\
\hline $2^{\circ}$ & 5611 & Restaurante & 14 & 7,7 & 4530 & Peças automotivas & 12 & 5,5 \\
\hline $3^{\circ}$ & 4520 & $\begin{array}{l}\text { Reparação } \\
\text { automotiva }\end{array}$ & 11 & 6,1 & 5611 & Restaurante & 12 & 5,5 \\
\hline $4^{\circ}$ & 4712 & Minimercado & 9 & 5 & 4771 & Farmácia & 10 & 4,6 \\
\hline $5^{\circ}$ & 4781 & Varejo de roupas & 9 & 5 & 4712 & Minimercado & 9 & 4,1 \\
\hline $6^{\circ}$ & 4789 & Agropecuária & 9 & 5 & 4761 & Livraria & 8 & 3,7 \\
\hline $7^{\circ}$ & 4930 & $\begin{array}{l}\text { Transporte } \\
\text { rodoviário }\end{array}$ & 7 & 3,9 & 4789 & Agropecuária & 8 & 3,7 \\
\hline $8^{\circ}$ & 2512 & Metalúrgica & 6 & 3,3 & 4721 & Padaria & 7 & 3,2 \\
\hline 90 & 4721 & Padaria & 5 & 2,8 & 4763 & Loja de esportes & 7 & 3,2 \\
\hline $10^{\circ}$ & 4744 & $\begin{array}{l}\text { Materiais de } \\
\text { construção }\end{array}$ & 4 & 2,2 & 4755 & Loja de tecidos & 6 & 2,7 \\
\hline & & Outros & 83 & 45,7 & & Outros & 89 & 40,5 \\
\hline
\end{tabular}

Fonte: Dados secundários produzidos pelos autores (2018).

Em vista dos dados apresentados, percebe-se que o empreendedorismo feminino é bastante presente na região analisada, sendo as empresas administradas por mulheres maioria na região considerada e as informaçóes elencadas ajudam a compreender o contexto analisado no sentido de promover o desenvolvimento da regiáo como um todo, uma vez que a medida que novos empreendimentos são concretizados toda a sociedade beneficia-se através da geração de emprego e renda (HISRICH; PETERS; SHEPHERD, 2014).

\section{Considerações finais}

Estudar as características das empresas administradas por mulheres é um importante motivo para fortalecer o empreendedorismo feminino e, por consequência, favorecer o desenvolvimento regional, por meio de novos investimentos e da geração de emprego e renda. O histórico demográfico da Região do Médio Alto Uruguai sinaliza mudanças quanto à permanência da populaçáo e aumento demográfico feminino. Aliados, esses dois fatores podem indicar maior participação e interesse pelo desenvolvimento com o fortalecimento do empreendedorismo, incentivados pelo crescimento satisfatório dos setores produtivos na região.

Os resultados deste estudo permitiram identificar que as mulheres são maioria na gestão das empresas da regiáo. Além disso, apesar de mais jovens, são também mais escolarizadas e responsáveis pela abertura de um número maior de empresas nos últimos anos, se comparado àquelas fundadas por homens. Além disso, o comércio tem sido o segmento preferido pelas empreendedoras, que atuam principalmente 
no varejo de roupas. Contudo, as empresas geridas por mulheres empregam menos pessoas do que as administradas por homens.

Não se buscou com esta pesquisa discutir qualquer dicotomia de gênero, mas analisar o perfil e o desempenho dos empreendimentos femininos e a sua contribuição para o desenvolvimento da regiáo, de maneira a fomentar açôes que venham a qualificar esses negócios e a garantir a sua sobrevivência. Assim, entende-se que a participação feminina nos segmentos da indústria e dos serviços pode ser encorajada.

Da mesma forma, devido à relevância da mulher no mercado de trabalho e à sua importância no empreendedorismo, entende-se que o presente estudo contribui com outros focados no empreendedorismo da mulher, tema emergente nas pesquisas atuais, com lacunas a serem preenchidas, especialmente em países em desenvolvimento. Indica-se, assim, que novos estudos podem ser realizados com o intuito de identificar a formação em gestão e as competências gerenciais das mulheres à frente dos negócios. Ainda, deve-se empreender esforços em estudos comparativos que avaliem o desempenho das empresas administradas por mulheres, com aquelas administradas por homens.

À guisa de conclusão aponta-se como limitação do estudo, a utilização de uma amostra de empresas de uma única região, o que requer cautela na generalização dos resultados. Da mesma forma, as análises foram realizadas através de dados que não permitiram traçar qualquer relação entre variáveis, por isso trata-se de um estudo meramente descritivo.

\section{Referências}

ALPERSTEDT, G. D.; FERREIRA, J. B.; SERAFIM, M. C. Empreendedorismo feminino:

dificuldades relatadas em histórias de vida. Revista de Ciências da Administraçáo, v. 16, n. 40, 2014.

AMORE, M. D.; GAROFALO, O.; MINICHILLI, A. Gender interactions within the family firm. Management Science, v. 60, n. 5, p. 1083-1097, 2014.

AVENI, A.; NUNES, M. S. C. N. F.; CRUZ, M. S. L. A. Um estudo do comportamento de mulheres empreendedoras no distrito federal. 2012.

BARRETT, M. Revisiting women's entrepreneurship: Insights from the family-firm context and radical subjectivist economics. International Journal of Gender and Entrepreneurship, v. 6, n. 3, p. 231254, 2014.

BURT, R. S. The Contingent Value of Social Capital, Administrative Science Quaterly 42 (2): 339-365. CrossRef Google Scholar, 1997.

CODEMAU - CONSELHO REGIONAL DE DESENVOLVIMENTO DO MÉDIO ALTO URUGUAI. Plano Estratégico de Desenvolvimento da Regiáo do Médio Alto Uruguai:2015-2030: CODEMAU/ Organizadores: Edemar Girardi... [et al.] - Frederico Westphalen, RS: Grafimax, 2017.

COLE, P. M.; JOHNSON, K. An exploration of successful copreneurial relationships postdivorce.

Family Business Review, v. 20, n. 3, p. 185-198, 2007. 
CRUZ, C.; JUSTO, R.; DE CASTRO, J. O. Does family employment enhance MSEs performance? Integrating socioemotional wealth and family embeddedness perspectives. Journal of Business Venturing, v.27, n.1, 62-76, 2012.

DANES, S. M.; STAFFORD, K.; LOY, J. T. Family business performance: The effects of gender and management. Journal of Business Research, v. 60, n. 10, 1058-1069, 2007.

DOLABELA, F. Oficina do empreendedor. Rio de Janeiro: Sextante, 2008.

DORNELAS, J. C. de A. Empreendedorismo, transformando ideias em negócios. Rio de Janeiro: Elsevier, 2014.

DRUCKER, P. F. Inovação e Espírito Empreendedor (Entrepeneurship) Prática e Princípios. São Paulo: Pioneira, 1987.

DRUCKER, P. O líder do futuro. São Paulo: Futura, 1996.

GEM - GLOBAL ENTREPRENEURSHIP MONITOR. Empreendedorismo no Brasil: 2011 / (Coord.) Simara Maria de Souza Silveira Greco; Curitiba: IBQP, 2011.

GEM- GLOBAL ENTREPRENEURSHIP MONITOR. Empreendedorismo no Brasil: 2015 (Coord.) Simara Maria de Souza Silveira Greco. Curitiba: IBQP, 2016.

GEM - GLOBAL ENTREPRENEURSHIP MONITOR. Empreendedorismo no Brasil: 2016 I Coordenação de Simara Maria de Souza Silveira Greco; diversos autores -- Curitiba: IBQP, 2017.

GUNDRY, L. K.; BEN-YOSEPH, M. Women entrepreneurs in Romania, Poland, and the United States: Cultural and family influences on strategy and growth. Family Business Review, v. 11, n. 1, p. 61-73, 1998.

HARVESTON, P. D.; DAVIS, P. S.; LYDEN, J. A. Succession planning in family business: The impact of owner gender. Family Business Review, v. 10, n. 4, 373-396, 1997.

HISRICH, R. D.; PETERS, M. P.; SHEPHERD, D. A. Empreendedorismo. 9 ed. Porto Alegre: AMGH Editora, 2014.

HISRICH, R. D.; FÜLÖP, G. Women entrepreneurs in family business: The Hungarian case. Family Business Review, v. 10, n. 3, p. 281-302, 1997.

KICKUL, J.; LIAO, J.; GUNDRY, L.; IAKOVLEVA, T. Firm resources, opportunity recognition, entrepreneurial orientation and performance: the case of Russian women-led family businesses. International Journal of Entrepreneurship and Innovation Management, v. 12, n. 1, p. 52-69, 2010 .

LUSSIER, R. N.; SONFIELD, M. C. A comparison of family-member and non-family-member managers in American family businesses. Academy of Entrepreneurship Journal, v. 13, n. 2, p. 31, 2007. 
PEARSON, A. W.; CARR, J. C.; SHAW, J. C. Toward a theory of familiness: A social capital perspective. Entrepreneurship theory and practice, v. 32, n. 6, p. 949-969, 2008.

ROBINSON, S.; STUBBERUD, H. A. All in the family: entrepreneurship as a family tradition. International Journal of Entrepreneurship, v. 16, 2012.

SCHUMPETER, J. A. Teoria do desenvolvimento econômico: Uma investigaçáo sobre lucros, capital, crédito, juro e o ciclo econômico. São Paulo: Abril Cultural, 1971.

SEBRAE - Serviço de Apoio à Micro e Pequenas Empresas. Negócio a Negócio: oportunidade para crescer. Disponível em: https://www.sebrae.com.br/momento/quero-melhorar-minha-empresa/acesse/ negocio-a-negocio/. Acesso em: 22 abril/2017.

SHANE, S.; VENKATARAMAN, S. The promise of entrepreneurship as a field of research. Academy of Management Review, v.25, n.1, p.217-226, 2000.

SILVA, M. S.; LASSO, S. V.; MAINARDES, E. W. Características do empreendedorismo feminino no brasil. Revista Gestáo e Desenvolvimento, v. 13, n. 2, p. 150-167, 2016.

SIRMON, D. G.; HITT, M. A. Managing resources: Linking unique resources, management, and wealth creation in family firms. Entrepreneurship theory and practice, v. 27, n. 4, p. 339-358, 2003.

WELSH, D. H. B., MEMILI, E., KACIAK, E. AHMED, S. Sudanese women entrepreneurs. Journal of Developmental Entrepreneurship, v. 18, n. 02, p. 1350013, 2013.

WELSH, D. H. B.; MIMELI, E.; KACIAK, E.; SADOON, A. Saudi women entrepreneurs: A growing economic segment. Journal of Business Research, v. 67, n. 5, p. 758-762, 2014.

ZAPALSKA, A. M.; NIEWIADOMSKA-BUGAJ, M.; RUDD, D. Female entrepreneurship in Transition Polish Economy, Problems and Perspectives in Management Journal, No. 2, Chapter 2: Management in Firms and Organizations. Google Scholar, p. 32-39, 2005. 